\title{
Analysis of Nonstationary Change of Annual Maximum Level Records in the Yangtze River Estuary
}

\author{
Guofang Li, ${ }^{1}$ Xinyi Xiang, ${ }^{2}$ and Caixiu Guo ${ }^{3}$ \\ ${ }^{1}$ State Key Laboratory of Hydrology-Water Resources and Hydraulic Engineering, College of Hydrology and Water Resources, \\ Hohai University, Nanjing 210098, China \\ ${ }^{2}$ School of Geographical Sciences, Southwest University, Chongqing 400715, China \\ ${ }^{3}$ College of Hydrology and Water Resources, Hohai University, Nanjing 210098, China
}

Correspondence should be addressed to Guofang Li; liguofang@hhu.edu.cn

Received 26 June 2015; Accepted 10 September 2015

Academic Editor: Alexander Gelfan

Copyright (C) 2016 Guofang Li et al. This is an open access article distributed under the Creative Commons Attribution License, which permits unrestricted use, distribution, and reproduction in any medium, provided the original work is properly cited.

Under the impact of climate change and human activities, the stationarity of hydrometeorological extreme value series has been losing in many regions, which makes occurrence rules of hydrometeorological extreme events more complicated. In this study, the efficiencies of trend test methods such as Spearman rank correlation test and Mann-Kendall test, as well as the efficiencies of change-point test methods such as moving T test, moving rank sum test, Pettitt test, and sequential Mann-Kendall test were analyzed quantitatively through Monte Carlo simulation. Five representative level stations in the Yangtze River estuary were selected, and the methods listed above were used in the trend and change-point detection of the annual maximum tidal level records in the period of 1950-2008. It was found that obvious rising tendency existed in the annual maximum tidal level series for all these 5 stations, and year 1980 (for 3 stations) and year 1979 (for 2 stations) were statistically significant change-points. Two subseries were divided with the change-point as the dividing point for all these actual series in the stations. Frequency analyses were carried out, respectively, for all of the subseries, and the impact of nonstationary changes in annual maximum tidal levels on probability distribution was evaluated quantitatively.

\section{Introduction}

In a relatively stable environment, hydrometeorological extreme value series are often seen as pure random variables drawn independently and randomly from the identical population distribution. The statistical parameter of population distribution can be estimated from the instrument records by hydrological frequency analysis. However, under the impact of climate change and human activities, the stationarity of hydrometeorological extreme value series has been losing in many regions in the world. In view of the magnitude and ubiquity of the hydroclimatic change, Milly et al. [1] asserted that stationarity should no longer serve as a default assumption in water-resource risk assessment and planning, and a suitable successor should be found for human adaptation to changing climate.

By now, there are numerous studies focused on trend detection methods [2-10] and change-point detection methods [11-20], which have been used in the trends and change-points detection for rainfall, runoff, evaporation, temperature, and sediment discharge worldwide [21-30]. However, in these reports, there are seldom researches on the efficiencies of variation detection methods and the reasons for nonstationary changes. Owing to the limited understanding of the driving factors and mechanisms of hydrometeorological extreme value sequence variation, evaluation of water resources and flood risk under changing environment has become the focus and challenge in current researches.

The area around the Yangtze River estuary is one of the most developed regions in China with a high density of population, high speed of urbanization, and high vitality of economic development. Considering its low and flat topography, together with the frequent occurrence of storm surges, flood prevention was mainly realized through embankment projects in this area. With the global climate change, rapid urbanization and hydraulic engineering constructions have taken place in this area. Therefore, it is necessary to detect the nonstationary change of annual maximum tidal level in 

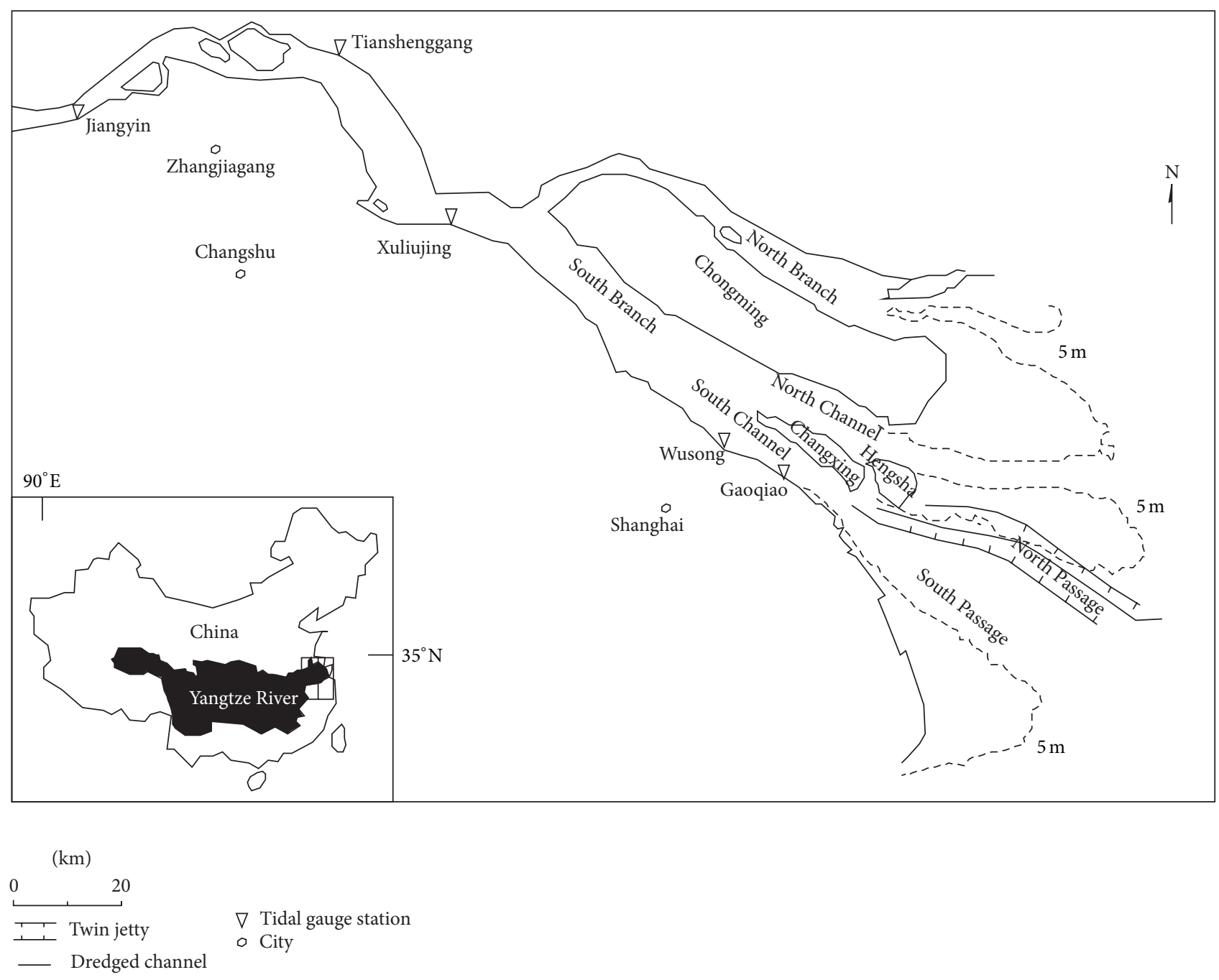

FIgURE 1: Locations of typical tidal gauge stations in the Yangtze River estuary.

the Yangtze River estuary and reevaluate the risk of annual maximum level exceeding certain extreme values, so as to provide scientific foundation for flood protection.

\section{Study Area and Related Data}

As the longest $(6300 \mathrm{~km})$ river in China, the Yangtze River extends from the Qinghai-Tibet Plateau and runs eastward into the East China Sea. Datong hydrological station, located at $642 \mathrm{~km}$ upstream of the river mouth, which is just free from tidal influences during low flow season, was selected as the control station of upstream discharge in this study. The study area is located in the Yangtze River estuary, which can be characterized as a system of tidal channels of threeorder bifurcation with four outlets into the sea (Figure 1). The North and South Branches are the first-order bifurcation. These branches are separated by the Chongming Island. The South Branch can be further divided into the North Channel and the South Channel by Changxing Island and Hengsha Island. The South Channel can be deeply divided into the North Passage and the South Passage by the Jiuduansha shoal.
At present, the South Branch is the main channel carrying water and sediment.

In this study, 5 national tide stations in the Yangtze River estuary were selected as the representative stations, namely, Jiangyin, Tianshenggang, Xuliujing, Wusong, and Gaoqiao, the locations of which were shown in Figure 1. Annual maximum tidal level records during the period from 1950 to 2008 of these stations were used. All these data were monitored data provided by the Yangtze River Water Conservancy Commission, Ministry of Water Resources of China, except for the data from 1961 to 1981 in Xuliujing station, the data from 1950 to 1953 in Tianshenggang station, and the data from 1950 to 1964 in Gaoqiao station, which were deduction data obtained by interpolation method.

\section{Methodology}

3.1. Trend Test Methods. Many methods have been developed to detect the tendency in hydrometeorological variable. In this study, Spearman rank correlation test and Mann-Kendall test were investigated. 
3.1.1. Spearman Rank Correlation (SRC) Test. The original sequence of time order $X_{i}(i=1,2, \ldots, n)$ is rearranged and renumbered from small to large (starting from 1 ); the number corresponding to every value is defined as its rank $R_{i}$. In SRC test, the null hypothesis is that there is no trend in the sequence. The test statistic $t_{\mathrm{SRC}}$ is calculated with (1) as follows (for details, see [29]):

$$
t_{\mathrm{SRC}}=r_{\mathrm{SRC}}\left(\frac{n-2}{1-r_{\mathrm{SRC}}^{2}}\right)^{1 / 2},
$$

where $n$ is the length of time series and $r_{\text {SRC }}$ is Spearman rank correlation coefficient, which is given by

$$
r_{\mathrm{SRC}}=1-\frac{6 \sum_{i=1}^{n}\left(R_{i}-i\right)^{2}}{n^{3}-n},
$$

where $i$ is the chronological order and $R_{i}$ is the rank of observation $X_{i}$ corresponding to the chronological order of $i$.

Statistic $t_{\text {SRC }}$ is almost in a $t$-distribution with degree of freedom $v=n-2$. The critical value $t_{\alpha / 2}$ is obtained based on $v$ and the significance level $\alpha$. If $\left|t_{\text {SRC }}\right| \leq t_{v, \alpha / 2}$, the null hypothesis should be accepted, or the null hypothesis should be rejected.

3.1.2. Mann-Kendall (MK) Test. The MK test is a nonparametric rank based test $[2,3]$. In MK test, the null hypothesis is that there is no trend in the sequence, and the test statistic $S$ is defined as follows:

$$
S=\sum_{i=2}^{n} \sum_{j=1}^{i-1} \operatorname{sgn}\left(x_{i}-x_{j}\right),
$$

among which $n$ is the length of time series, $x_{j}$ and $x_{i}$ are both values in the series, and $\operatorname{sgn}()$ is a sign function:

$$
\operatorname{sgn}\left(x_{i}-x_{j}\right)= \begin{cases}-1 & \text { for }\left(x_{i}-x_{j}\right)<0 \\ 0 & \text { for }\left(x_{i}-x_{j}\right)=0 \\ 1 & \text { for }\left(x_{i}-x_{j}\right)>0\end{cases}
$$

If $n \geq 10$, the statistic $S$ is almost in normal distribution; the standardized statistic $Z$ is calculated with the following equation:

$$
Z= \begin{cases}\frac{(S-1)}{\sqrt{n(n-1)(2 n+5) / 18}} & S>0, \\ 0 & S=0, \\ \frac{(S+1)}{\sqrt{n(n-1)(2 n+5) / 18}} & S<0 .\end{cases}
$$

The statistic $Z$ follows standard normal distribution, and the critical value $Z_{\alpha / 2}$ is calculated based on the significance level $\alpha$. If $|Z|>Z_{\alpha / 2}$, the null hypothesis should be rejected, or the null hypothesis should be accepted.

In this study, we selected 0.05 as significance level in all statistical tests and considered only monotonically increasing or decreasing trend, even though there could be other patterns of trend.
3.2. Change-Point Test Methods. Different methods have been developed to test the change-points in the hydrometeorological variables. In this study, moving $\mathrm{T}$ test [31], moving rank sum test [18], Pettitt test [32], and sequential MannKendall test [29] methods were studied.

3.2.1. Moving $T$ (MT) Test. In the moving $\mathrm{T}$ test, to find out the change-point, we successively set the change-point in different time point $n_{1}\left(1 \leq n_{1} \leq n-1\right)$. For every time point, the original series $X_{t}$ were divided into two subseries $\left(x_{1}, x_{2}, \ldots, x_{n_{1}}\right)$ and $\left(x_{n_{1}+1}, x_{n_{1}+2}, \ldots, x_{n_{1}+n_{2}}\right)$, among which $n_{1}+n_{2}=n$. The null hypothesis is that, before and after the change-point, both subseries are from the same population. Statistic $t$ is calculated with (6) as follows:

$$
=\frac{a_{1}-a_{2}}{\sqrt{\left(\left(n_{1}-1\right) s_{1}^{2}+\left(n_{2}-1\right) s_{2}^{2}\right) /\left(n_{1}+n_{2}-2\right)} \sqrt{1 / n_{1}+1 / n_{2}}},
$$

where $n_{1}$ and $n_{2}$ are the lengths of the two subseries; $a_{1}$ and $a_{2}$ are the averages of the two subseries; $s_{1}$ and $s_{2}$ are the variances of the two subseries.

Null hypothesis is assumed to be true, and statistic $t$ obeys $t$-distribution with the freedom degree $v=n_{1}+n_{2}-2$. The critical value $t_{\alpha / 2}$ can be obtained based on the freedom degree $v$ and the significance level $\alpha$. If $|t|>t_{\alpha / 2}$, the null hypothesis should be rejected, or the null hypothesis should be accepted.

Responding to the different time point $n_{1}$, a series of statistics $t$ are obtained. In all the possible change-points which could meet the condition that $|t|>t_{\alpha / 2}$, the point which can make $|T|$ statistics the maximum value is the most possible change-point.

3.2.2. Moving Rank Sum (MRS) Test. In the moving rank sum test, to find out the change-point, we successively set the change-point in different time point $\tau_{0}\left(1 \leq \tau_{0} \leq n-1\right)$. For every time point, the original series were divided into two subseries whose lengths are $n_{1}$ and $n_{2}$ separately, among which $n_{1}+n_{2}=n$. The null hypothesis of MRS test is that, before and after the change-point, the subseries are from the same population. The rank sum of the subseries with shorter length is $W$, and the rank sum test can be carried out with statistic $U$, which is calculated with the following equation:

$$
U=\frac{W-n_{1}\left(n_{1}+n_{2}+1\right) / 2}{\sqrt{n_{1} n_{2}\left(n_{1}+n_{2}+1\right) / 12}},
$$

where $n_{1}$ and $n_{2}$ are the lengths of the two subseries. When $n_{1}>10$ and $n_{2}>10, U$ obeys the normal distribution approximately. Based on significance level $\alpha$, critical value $U_{\alpha / 2}$ can be obtained. When $|U|>U_{\alpha / 2}$, the null hypothesis should be rejected, or the null hypothesis should be accepted.

Responding to the different time point $\tau_{0}$, a series of statistics $U$ are obtained. In all the possible change-points $\tau_{0}$ which could meet the condition that $|U|>U_{\alpha / 2}$, the point which can make $|U|$ statistics the maximum value was the most possible change-point. 
3.2.3. Pettitt Test. Because Pettitt test is one of the nonparametric tests, it is more robust against outliers and skewed distributions. The length of the time series $X_{t}(t=1,2, \ldots, n)$ is $n$, and the statistic can be defined as follows:

$$
\begin{aligned}
& U_{t, n}=\sum_{i=1}^{t} \sum_{j=t+1}^{n} D_{i, j} \quad(1 \leq t \leq n-1), \\
& D_{i, j}=\operatorname{sgn}\left(x_{i}-x_{j}\right)=\left\{\begin{array}{lc}
-1 & \text { for }\left(x_{i}-x_{j}\right)<0, \\
0 & \text { for }\left(x_{i}-x_{j}\right)=0, \\
1 & \text { for }\left(x_{i}-x_{j}\right)>0 .
\end{array}\right.
\end{aligned}
$$

Setting $k_{0}=\max \left|U_{t, n}\right|(1 \leq t \leq n-1), t_{0}$ corresponding to $k_{0}$ is the possible change-point. The significance of the possible change-point can be computed using

$$
P_{0}=2 \exp \left\{-\frac{6 k_{0}^{2}}{\left(n^{3}+n^{2}\right)}\right\}
$$

If $P_{0} \leq 0.5, t_{0}$ can be taken as the significant change-point statistically, based on which the first-order change-point of the series can be detected. The original series is divided into two subseries by this first-order change-point, and then the new change-points for these subseries can be detected using the same method.

\subsubsection{Sequential Mann-Kendall (SQMK) Test. Mann-Kendall} test was developed to detect some trends in the time series [2, 3 ] at the beginning, based on which a sequential version was proposed [33], which made it possible to detect the beginning of abrupt change in mean. SQMK test, which can be used to make progressive and retrograde analyses on the MK test, will produce sequential values $u(t)$ and $u^{\prime}(t)$, respectively. These are standardized normal variables with the mean value being 0 and the standard deviation being 1 . The intersection of $u(t)$ and $u^{\prime}(t)$ will be a change-point if it occurs between the critical value of $-U_{\alpha / 2}$ and $+U_{\alpha / 2}$. The detection of climate abrupt change with SQMK was discussed by Wang and Fu [5]; for the sake of brevity, we do not describe it in detail in this paper.

3.3. Frequency Analysis Methods. In hydrological frequency analysis, it is assumed that the samples are drawn independently and randomly from the identical population distribution, the function form of which has not been proved in theory. At present, there are more than 20 popular distribution function forms around the world, including PIII, LP-III, GEV, EV, LN, and K-M. P-III distribution is considered as the most suitable and widely used function for the frequency analysis of hydrologic variables in most regions of China. In this study, P-III distribution function was used as the fitting function for annual maximum tidal level, the probability density function of which is as follows:

$$
f(x)=\frac{\beta^{\alpha}}{\Gamma(\alpha)}\left(x-a_{0}\right)^{\alpha-1} e^{-\beta\left(x-a_{0}\right)} \quad \alpha>0, \beta>0,
$$

where $\Gamma(\alpha)$ is the Gamma function of $\alpha ; \alpha, \beta$, and $a_{0}$ are the shape, scale, and location parameters for P-III distribution, respectively; they can be obtained by three statistical parameters of the population (mean value $\mu$, coefficient of variation $C_{V}$, and coefficient of skew $C_{S}$ ):

$$
\begin{aligned}
\alpha & =\frac{4}{C_{S}^{2}} ; \\
\beta & =\frac{2}{\mu \cdot C_{V} \cdot C_{S}} ; \\
a_{0} & =\mu\left(1-\frac{2 C_{V}}{C_{S}}\right) .
\end{aligned}
$$

There have been numerous researches on hydrological frequency curve parameters estimation, such as conventional moments method, curve-fitting method, maximum likelihood method, probability weighted moment method [34, 35], weighted function method [36, 37], and L-moment methods [38]. The comparisons of parameter estimation methods could be referred to Sankarasubramanian and Sirnivasan [39] and Guo [40]. In this study, curve-fitting method was used to determine these 3 parameters in P-III distribution [41], and the parameters computed with L-moment method were taken as the original values for the fitting curve.

\section{Results and Discussion}

4.1. Analysis on the Efficiency of Trend Test Methods. Considering that the basis for hypothesis test is the small probability event principle, there may exist two kinds of typical errors: type-I error, where null hypothesis is rejected when the null hypothesis is true; type-II error, where null hypothesis is accepted when the alternative hypothesis is true. The probability of type-I error is equal to significance level. For selected significance level, low probability of type-II error indicates more powerful test. The efficiency of the test is defined as the probability of correctly detecting the trend when it is present. For selected $\alpha$, the efficiency of trend test is directly associated with the test technique, trend magnitude, sample size, and random fluctuation magnitude.

To analyze efficiencies of SRC test and MK test for detecting trend, taking the annual maximum tidal level series as example, Monte Carlo experiment scheme was designed as follows: (1) assume the time series were the composition of random component and trend component, where the magnitude of linear trends were defined as $0.006 \mathrm{~m} / \mathrm{a}, 0.013 \mathrm{~m} / \mathrm{a}$, and $0.019 \mathrm{~m} / \mathrm{a}$, respectively; (2) the P-III distribution parameters of random component were known, where the average was 0 , the coefficient of skew Cs was 1.10 , and the standard deviations were $0.175 \mathrm{~m}, 0.350 \mathrm{~m}$, and $0.525 \mathrm{~m}$, respectively; (3) the sample sizes were selected as $20,30,40,50,60,80$, and 100 , respectively.

In this study, 9 combinations of 3 linear trends and 3 random fluctuations were investigated; for every combination, 7 different lengths were set, and with each length, 20000 series were simulated by Monte Carlo approach. The total number of the series is $3 \times 3 \times 7 \times 20000$. SRC test and MK test were carried out on all the $63 \times 20000$ series, and the ratio 


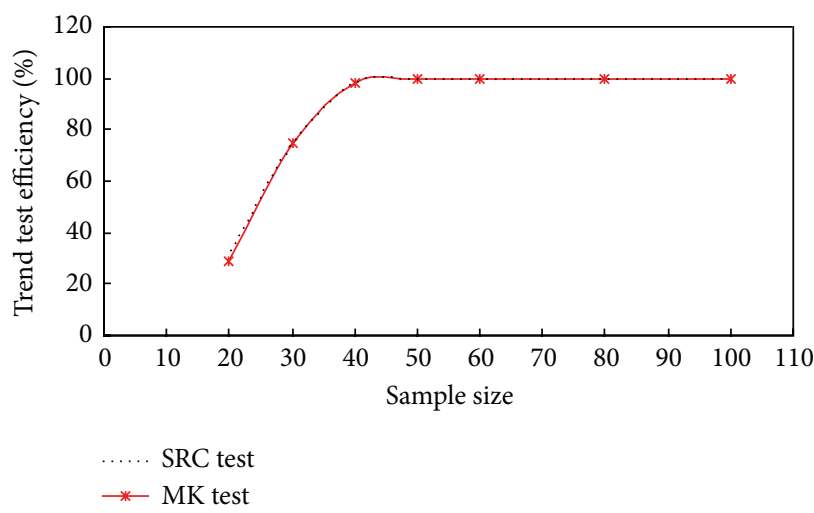

(a) Linear trend was $0.019 \mathrm{~m} / \mathrm{a}$ and standard deviation was $0.350 \mathrm{~m}$

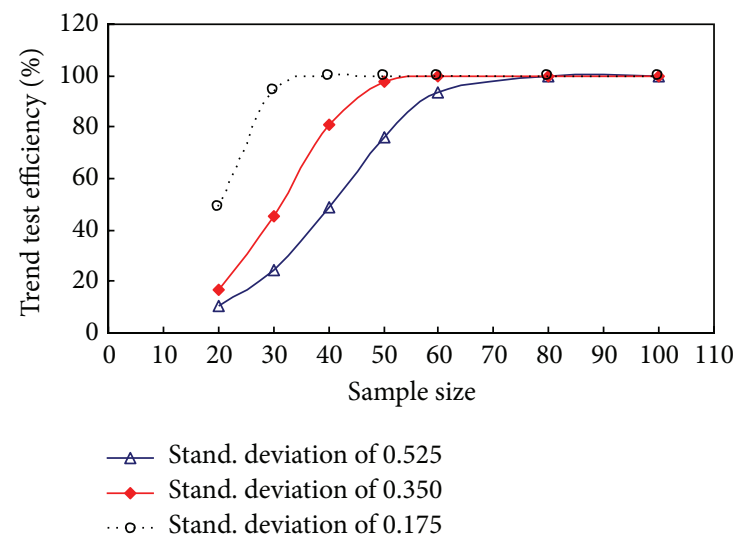

(b) Linear trend was $0.013 \mathrm{~m} / \mathrm{a}, \mathrm{SRC}$ test

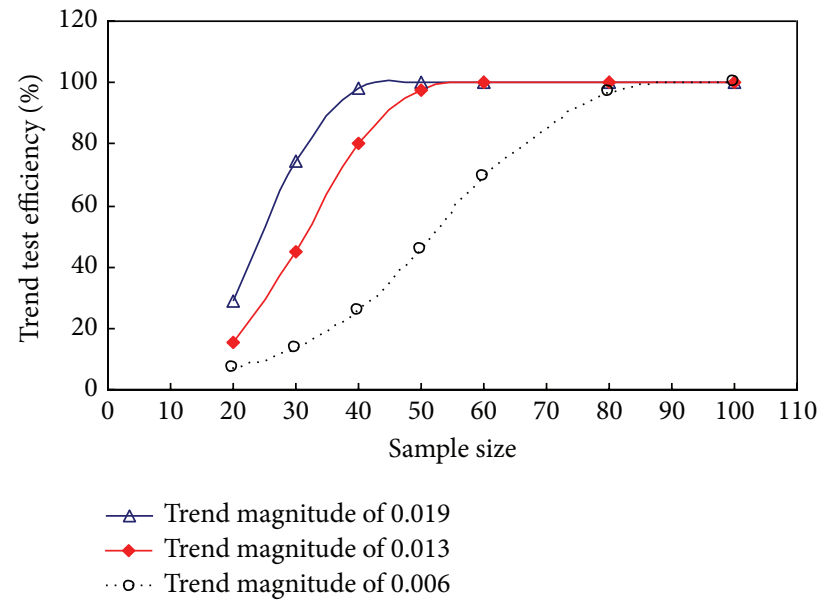

(c) Standard deviation was $0.350 \mathrm{~m}, \mathrm{MK}$ test

FIGURE 2: Relationship between trend test efficiency and sample size in different combinations.

TABLE 1: Efficiencies of different tests for detecting change-point under different compositions.

\begin{tabular}{|c|c|c|c|c|c|c|}
\hline \multirow{2}{*}{$\begin{array}{l}\text { Standard deviation of } \\
\text { random component }\end{array}$} & \multirow{2}{*}{ Shift in mean } & \multirow{2}{*}{$\begin{array}{l}\text { Ratio of shift in mean to standard } \\
\text { deviation of random component }\end{array}$} & \multicolumn{4}{|c|}{ Efficiency of test for detecting change-point } \\
\hline & & & MT test & MRS test & Pettitt test & SQMK test \\
\hline 0.350 & 0.350 & 1 & 25.6 & 29.2 & 32.9 & 11.0 \\
\hline 0.175 & 0.175 & 1 & 26.1 & 29.7 & 33.4 & 11.1 \\
\hline 0.525 & 0.525 & 1 & 26.2 & 29.6 & 33.3 & 11.2 \\
\hline 0.350 & 0.700 & 2 & 65.1 & 65.8 & 67.1 & 18.9 \\
\hline 0.175 & 0.350 & 2 & 65.5 & 66.0 & 67.3 & 19.1 \\
\hline 0.525 & 1.050 & 2 & 65.7 & 66.0 & 67.3 & 19.1 \\
\hline 0.350 & 1.050 & 3 & 87.5 & 86.3 & 86.8 & 21.2 \\
\hline 0.175 & 0.525 & 3 & 88.5 & 86.8 & 87.3 & 22.0 \\
\hline 0.525 & 1.575 & 3 & 88.4 & 86.9 & 87.3 & 21.3 \\
\hline 0.175 & 0.700 & 4 & 94.9 & 95.8 & 96.0 & 22.0 \\
\hline 0.175 & 1.050 & 6 & 98.9 & 99.7 & 99.7 & 22.2 \\
\hline
\end{tabular}

of correct detection of trend change in every 20000 series was recorded to evaluate the trend test efficiency in corresponding condition.

In Figure 2, the relationship between trend test efficiency and sample size with different compositions of trend magnitude and standard deviation of random component was presented, from which three conclusions can be drawn as follows:

(i) With the other factors being kept the same, trend test efficiencies of SRC test and MK test were approximate.

(ii) With the other factors being kept the same, with the increase of random fluctuation, the trend test 
efficiency decreased, and with the decrease of random fluctuation, the trend test efficiency increased, indicating that random fluctuation may generate impact on trend test. For short time series with small trend change magnitude and big random fluctuation, the trend test efficiency was low.

(iii) No matter what the kind of the composition of random component and trend component was, trend test efficiency increased with the increase of sample size. If the sample size was above 50 years, the trend test efficiency was high in general.

4.2. Analysis on the Efficiency of Change-Point Test Methods. To analyze the efficiencies of MT test, MRS test, Pettitt test, and SQMK test for detecting change-point, Monte Carlo experiment scheme was designed as follows taking the annual maximum tidal level series as an example: (1) it is assumed that the time series were composed of random component and shift component and that there is only change-point in the mean, even though there could be change-point both in the mean and in the variance; (2) the sample size was 50 and the change-point in the mean was just the middle point of the time series; (3) the parameters of the random component of P-III distribution were known, the mean value was 0 , the coefficient of skew $C_{S}$ was 1.10 , and the standard deviations were $0.175 \mathrm{~m}, 0.350 \mathrm{~m}$, and $0.525 \mathrm{~m}$, respectively; (4) when the standard deviation $\sigma$ was $0.175 \mathrm{~m}$, the shifts in mean were set as $1 \sigma, 2 \sigma, 3 \sigma, 4 \sigma$, and $6 \sigma$, respectively. When the standard deviation $\sigma$ was $0.35 \mathrm{~m}$, the shifts in mean were set as $1 \sigma$, $2 \sigma$, and $3 \sigma$, respectively. When the standard deviation $\sigma$ was $0.525 \mathrm{~m}$, the shifts in mean were set as $1 \sigma$ and $2 \sigma$, respectively.

For every one of the above mentioned 10 compositions of standard deviation and variation range of the mean, 20000 series with the length being 50 were generated by Monte Carlo approach. There were $10 \times 20000$ series in total. MT test, MRS test, Pettitt test, and SQMK test were carried out on all the series, and the ratio for correct detection of the change-point in every 20000 series was counted to evaluate the changepoint test efficiency with different composition.

Relationship between change-point test efficiency and ratio of shift in mean to standard deviation of random component was presented in Table 1 and Figure 3, from which several conclusions can be drawn as follows:

(i) With the other factors being kept the same, the efficiencies of MT test, MRS test, and Pettitt test for detecting change-point were approximative with each other, while the efficiency of SQMK test for detecting change-point was obviously low. SQMK test is widely used in the change-point test in hydrological series currently, but based on the statistical experiment it was found that the efficiency of SQMK test for detecting change-point was quite low.

(ii) With the fixed ratio of shift in mean to standard deviation of random component, the change-point test efficiencies of all these methods were approximate.

(iii) With the increase of ratio of shift in mean to standard deviation of random component, test efficiency

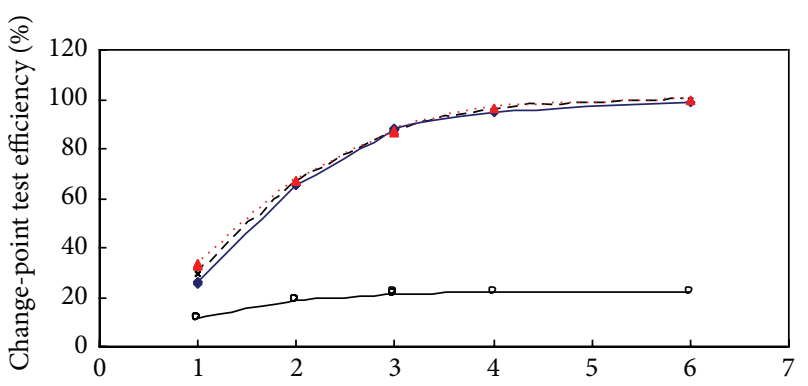

Ratio of shift in mean to standard deviation of random component

$\rightarrow$ MT test $\quad-*-$ MRS test
$\ldots$ Pettitt test $\quad \longrightarrow$ SQMK test

FIGURE 3: Relationship between change-point test efficiency and ratio of shift in mean to standard deviation of random component.

increased continuously, while the increase amplitude decreased gradually.

\subsection{Trend and Change-Point Detection of Annual Maximum} Tidal Level Series. SRC test and MK test were carried out for detecting trend in annual maximum tidal level series during the period from 1950 to 2008 in 5 representative tide level stations in Yangtze River estuary, namely, Jiangyin, Tianshenggang, Xuliujing, Wusong, and Gaoqiao, the results of which were presented in Table 2 . It was found there was increasing tendency for the annual maximum tidal levels in all these stations. MT test, MRS test, Pettitt test, and SQMK test were carried out for detecting change-point in annual maximum tidal level series during the period from 1950 to 2008 in these 5 stations. To evaluate the stability of the change-point test results with the change in samples (including the changes in sample size and sampling period), separate change-point tests were also carried out in the subseries during the periods of 1955-2008, 1960-2008, 19501998, and 1950-2003, the results of which were presented in Table 3. Annual maximum tidal level series during the period from 1950 to 2008 in these 5 stations were shown in Figure 4, and the statistics $U_{t, n}$ of Pettitt test were presented in Figure 5.

The following can be seen from Table 3:

(i) The results of MRS test and Pettitt test were almost the same. Even with the changes in samples and stations, results with high stability can be obtained. Change-points were concentrated in 1980 (Jiangyin, Tianshenggang, and Xuliujing stations) and 1979 (Wusong and Gaoqiao stations).

(ii) As for the results of MT test, with the changes in samples and stations, stable results can also be obtained. Almost half of the first change-points were concentrated in 1989 instead of in 1980 or in 1979 (by contrast, under the same condition, for the series in Jiangyin, Tianshenggang, and Xuliujing stations, the 3rd and the 4th change-points appeared in 1980; for the series in Wusong and Gaoqiao stations, the 3rd, 4 th, and 5th change-points appeared in 1979). 
TABLE 2: Trend detection for annual maximum level series of 1950-2008 in 5 stations.

\begin{tabular}{|c|c|c|c|c|c|c|}
\hline \multirow{2}{*}{ Station } & \multicolumn{3}{|c|}{ SRC } & \multicolumn{3}{|c|}{ MK } \\
\hline & Test statistic & Critical value & Test result & Test statistic & Critical value & Test result \\
\hline Jiangyin & 3.149 & 2.003 & 1 & 2.956 & 1.960 & 1 \\
\hline Tianshenggang & 4.534 & 2.003 & 1 & 4.009 & 1.960 & 1 \\
\hline Xuliujing & 4.415 & 2.003 & 1 & 3.865 & 1.960 & 1 \\
\hline Wusong & 3.048 & 2.003 & 1 & 3.087 & 1.960 & 1 \\
\hline Gaoqiao & 3.684 & 2.003 & 1 & 3.531 & 1.960 & 1 \\
\hline
\end{tabular}

" 1 " indicates upward trend.

TABLE 3: Change-point detection for annual maximum levels in 5 stations.

\begin{tabular}{|c|c|c|c|c|c|c|}
\hline Station & Method & $\begin{array}{c}\text { Change-point of } \\
1950-2008\end{array}$ & $\begin{array}{c}\text { Change-point of } \\
\text { 1955-2008 }\end{array}$ & $\begin{array}{c}\text { Change-point of } \\
\text { 1960-2008 }\end{array}$ & $\begin{array}{c}\text { Change-point of } \\
\text { 1950-1998 }\end{array}$ & $\begin{array}{c}\text { Change-point of } \\
\text { 1950-2003 }\end{array}$ \\
\hline \multirow{5}{*}{ Jiangyin } & MT & 1980 & 1980 & 1980 & 1980 & 1980 \\
\hline & MRS & 1980 & 1980 & 1980 & 1980 & 1980 \\
\hline & Pettitt & 1980 & 1980 & 1980 & 1980 & 1980 \\
\hline & SQMK & 1987 & 1985 & 1981 & 1990 & 1990 \\
\hline & Synthetical result study & 1980 & 1980 & 1980 & 1980 & 1980 \\
\hline \multirow{5}{*}{ Tianshenggang } & MT & 1989 & 1989 & 1989 & 1980 & 1989 \\
\hline & MRS & 1980 & 1980 & 1980 & 1980 & 1980 \\
\hline & Pettitt & 1980 & 1980 & 1980 & 1980 & 1980 \\
\hline & SQMK & 1987 & 1985 & 1981 & 1990 & 1989 \\
\hline & Synthetical result & 1980 & 1980 & 1980 & 1980 & 1980 \\
\hline \multirow{5}{*}{ Xuliujing } & MT & 1980 & 1980 & 1980 & 1980 & 1989 \\
\hline & MRS & 1980 & 1980 & 1980 & 1980 & 1980 \\
\hline & Pettitt & 1980 & 1980 & 1980 & 1980 & 1980 \\
\hline & SQMK & 1982 & 1987 & 1980 & 1989 & 1988 \\
\hline & Synthetical result & 1980 & 1980 & 1980 & 1980 & 1980 \\
\hline \multirow{5}{*}{ Wusong } & MT & 1989 & 1989 & 1989 & 1979 & 1989 \\
\hline & MRS & 1979 & 1979 & 1979 & 1979 & 1979 \\
\hline & Pettitt & 1979 & 1979 & 1979 & 1979 & 1979 \\
\hline & SQMK & 1980 & 1979 & 1979 & 1988 & 1988 \\
\hline & Synthetical result & 1979 & 1979 & 1979 & 1979 & 1979 \\
\hline \multirow{5}{*}{ Gaoqiao } & MT & 1989 & 1974 & 1989 & 1989 & 1989 \\
\hline & MRS & 1979 & 1979 & 1979 & 1979 & 1979 \\
\hline & Pettitt & 1979 & 1979 & 1979 & 1979 & 1979 \\
\hline & SQMK & 1980 & 1979 & 1979 & 1988 & 1988 \\
\hline & Synthetical result & 1979 & 1979 & 1979 & 1979 & 1979 \\
\hline
\end{tabular}

(iii) The change-points detected by SQMK test changed with the samples and the stations, which was not consistent with the results of the other methods. $\mathrm{Li}$ et al. [42] detected the change-points in hydrological series in the middle reach of Xijiang with movingF test, moving-T test, SQMK test, and Bayesian test, based on which the results of SQMK test were also proved to be with low stability.

(iv) The final change-points in the annual maximum tidal level series in these stations were synthesized based on the change-points detected by MT test, MRS test, Pettitt test, and SQMK test, and the results were presented in Table 3.
4.4. Reason Analysis on the Nonstationary Change of Annual Maximum Tidal Level. Tidal level in the Yangtze River estuary was mainly affected by such factors as upstream runoff, downstream tidal level, and the river channel storage capacity $[43,44]$; the above mentioned three factors were analyzed accordingly as follows.

4.4.1. Change of Upstream Runoff. Datong hydrological station was selected as the control station for analysis of runoff in the Yangtze River estuary. Based on recorded data, annual maximum runoff in Datong station was concentrated mainly in July and August, and the annual maximum tidal level in the Yangtze River estuary was also concentrated in July and 


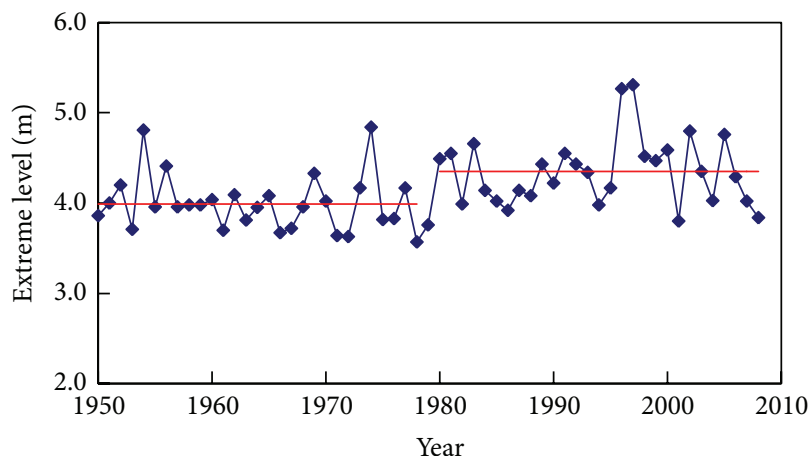

(a) Jiangyin

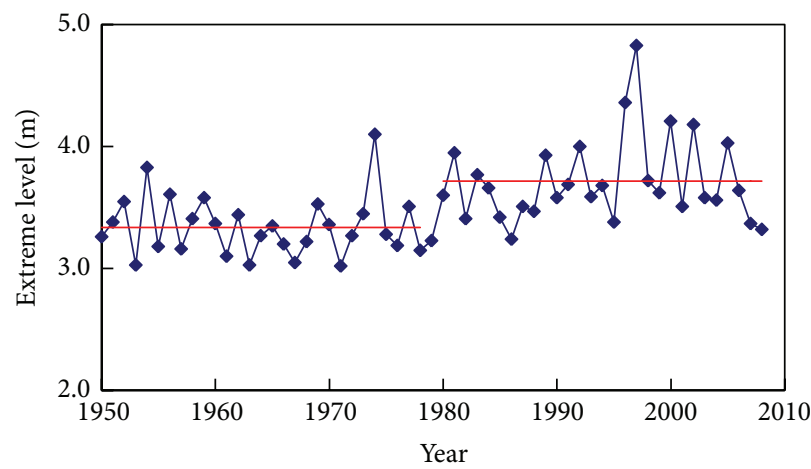

(c) Xuliujing

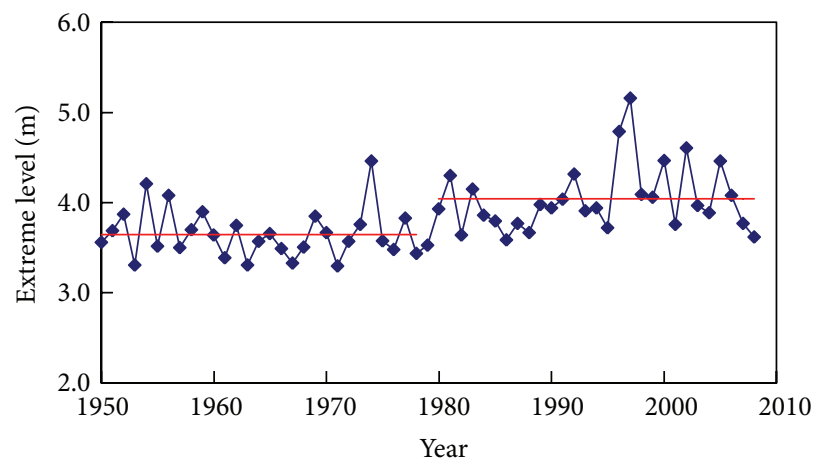

(b) Tianshenggang

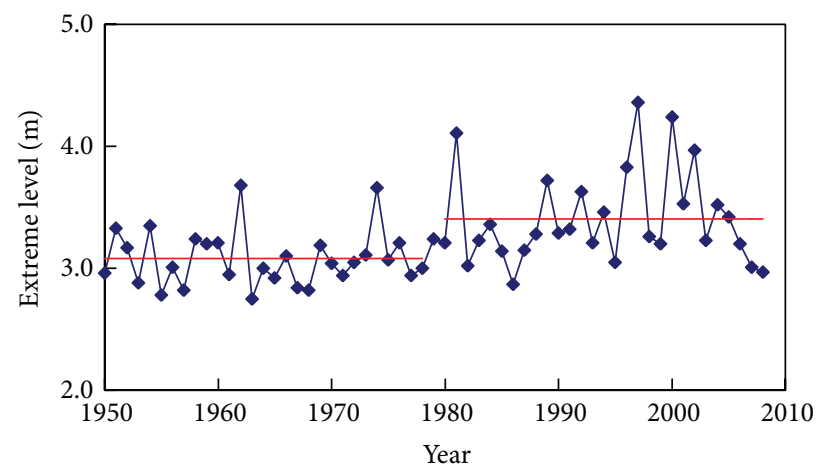

(d) Wusong

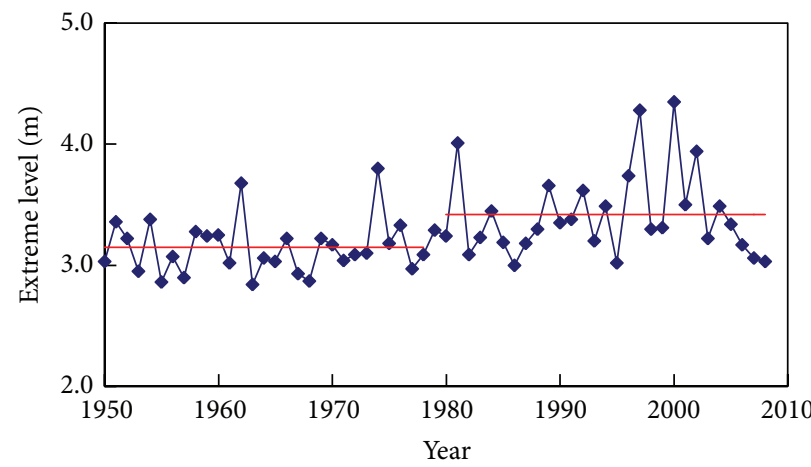

(e) Gaoqiao

FIGURE 4: Time series of annual maximum level for 5 stations during 1950-2008.
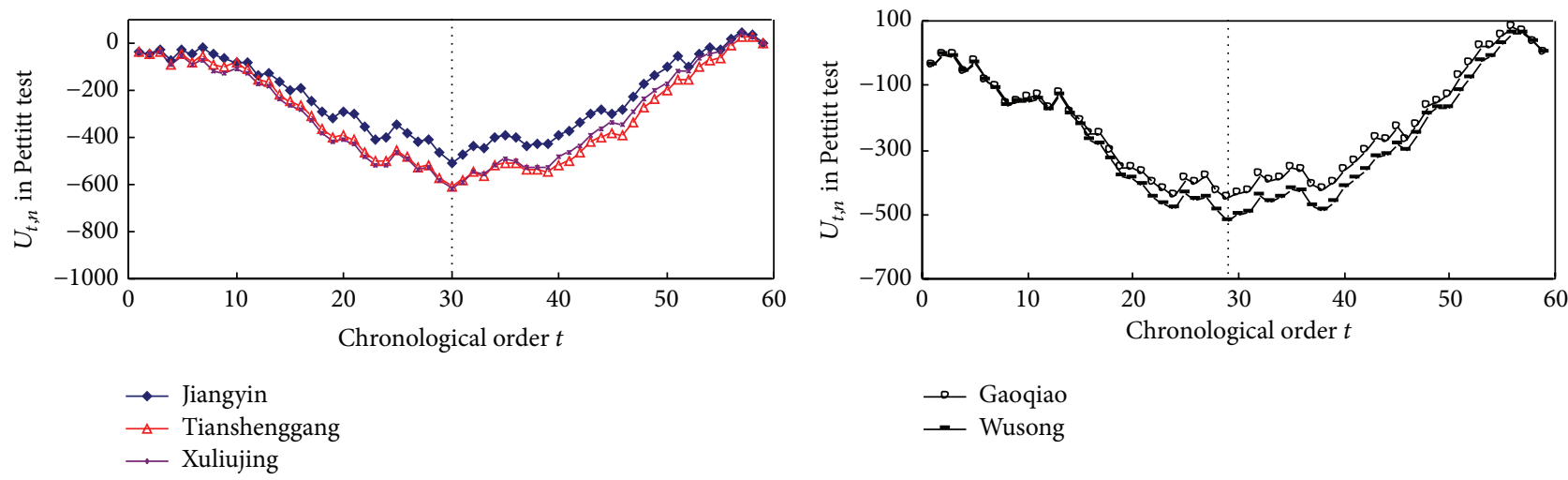

Figure 5: Sequential values of $U_{t, n}$ in Pettitt test for 5 stations during 1950-2008. 


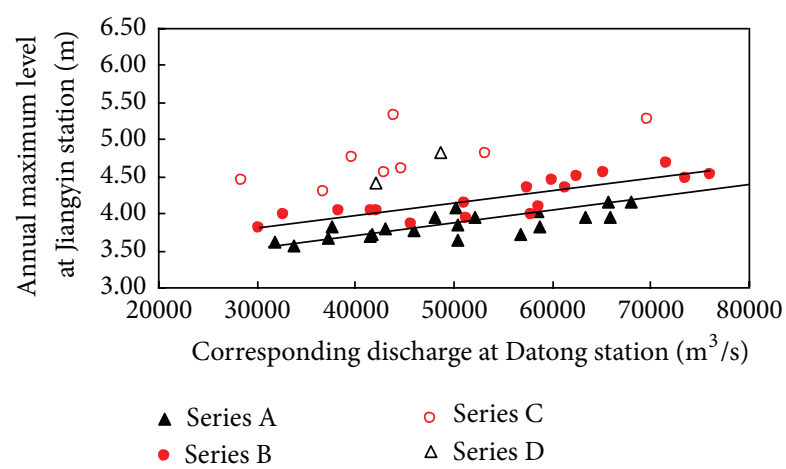

FIGURE 6: Relationship between annual maximum level in Jiangyin station and corresponding discharge in Datong station. (Series A: 1950-1979, without impact of typhoon; Series B: 1980-2005, without impact of typhoon; Series C: 1950-1979, with impact of typhoon; Series D: 1980-2005, with impact of typhoon.)

August. For example, in Jiangyin station and Tianshenggang station, probabilities of the annual maximum tidal level in July and August were $78.0 \%$ and $76.3 \%$, respectively.

In this study, trends and change-points for 3 series such as annual maximum discharge, average discharge in July, and average discharge in August during the period of 1950-2008 in Datong station were detected using SRC test, MK test, MT test, MRS test, and Pettitt test. It was found that there was no significant increasing tendency and change-point for these 3 discharge series, which was in coincidence with the conclusions of Qin et al. [45].

4.4.2. Change of Typhoons Activities. Climate change made the extreme weather events more frequently. In Figure 6, relationships between the annual maximum tidal level in Jiangyin station and corresponding discharge in Datong station during the periods 1950-1979 and 1980-2008 were presented. During the periods 1950-1979 and 1980-2008, numbers of typhoons exerting impact on Yangtze River estuary and leading to the annual maximum tidal level in Jiangyin station were 2 (typhoons numbers 5612 and 7413, indicated as " $\triangle$ " in Figure 6) and 7 (typhoons numbers $8114,9216,9608,9711,0012,0216$, and 0509, indicated as "o" in Figure 6), respectively. In Figure 6, it is indicated that the annual maximum tidal level in Jiangyin station was apparently affected by typhoon.

4.4.3. Change of River Channel Storage Capacity. It is found from Figure 6 that the annual maximum tidal level in Jiangyin station rose even with the same upstream runoff, which can be deemed as an evidence that the river channel storage capacity decreased. Main causes for such changes were as follows: (a) sluices construction in the tributaries, which would be closed in flooding season or when storm surges took place, preventing water stream running upward and limiting the storage space in the trunk stream; (b) enclosing tideland for cultivation and silting in the North Branch of Chongming Island reducing the water surface in the Yangtze River estuary. For example, because of the enclosing tideland for cultivation in Tonghaisha and Jiangxinsha, the river width of Xuliujing section decreased from $15.7 \mathrm{~km}$ at the beginning of the twentieth century to about $6 \mathrm{~km}$ today.

4.5. Impact of the Nonstationarity of Annual Maximum Tidal Level on Its Probability Distribution. For all these 5 stations, the annual maximum tidal level series during 19502008 were split into two subseries (before and after the change-point) and trend tests were performed for each of the two subseries separately. Considering the precondition for frequency analysis, samples should be drawn from the identical population, which should also be independent of each other. Sample autocorrelation test was carried out for evaluation of independence of the two subseries for all these stations. Since sample autocorrelation test was widely used $[46,47]$, we do not describe it in detail. The results of trend test and autocorrelation test are shown in Table 4, from which it can be seen that all of the subseries can be accepted as stationary series without serial correlation, making the frequency analysis reliable.

To carry out quantitative analysis on the probability distribution changes in these stations, frequency analysis was carried out on the annual maximum tidal level subseries before and after the change-point in each station. P-III distribution function was selected as the fitting function, the 3 parameters of which were determined with curvefitting method, and the initial parameters of the curve-fitting method were estimated by L-moment method. Through frequency analysis, annual maximum tidal level probability distributions before and after the change-point in Jiangyin, Tianshenggang, Xuliujing, Wusong, and Gaoqiao stations were obtained, which were presented in Figure 7. Distribution parameters and design annual maximum tidal level with different frequencies were listed in Table 5. Frequencies in Figure 7 and Table 5 were defined as $P$ (annual maximum tidal level $\geq$ certain given value). It was evident that obvious changes took place in the probability distribution of annual maximum tidal level before and after the change-point. With the fixed frequency, the design water level increased significantly. For example, design value with $0.1 \%$ frequency (1000-year return period) increased by $0.80-1.40 \mathrm{~m}$, design value with $1 \%$ frequency (100-year return period) increased by $0.60-1.00 \mathrm{~m}$, and design value with $10 \%$ frequency (10-year return period) increased by $0.50 \mathrm{~m}$.

As for Jiangyin, Tianshenggang, Xuliujing, Wusong, and Gaoqiao stations, before the change-point, probability of annual maximum tidal levels being above $5.82 \mathrm{~m}, 5.29 \mathrm{~m}$, $4.82 \mathrm{~m}, 4.46 \mathrm{~m}$, and $4.59 \mathrm{~m}$ was $0.1 \%$ (1000-year return period); after the change-point, probabilities of annual maximum tidal levels being above $5.82 \mathrm{~m}, 5.29 \mathrm{~m}, 4.82 \mathrm{~m}, 4.46 \mathrm{~m}$, and $4.59 \mathrm{~m}$ were $1.0 \%, 1.9 \%, 2.4 \%, 3.2 \%$, and $2.4 \%$, respectively (corresponding to 104-, 53-, 41-, 31-, and 42-year return periods); before the change-point, probability of annual maximum tidal levels being above $5.17 \mathrm{~m}, 4.70 \mathrm{~m}, 4.29 \mathrm{~m}, 3.97 \mathrm{~m}$, and $4.06 \mathrm{~m}$ was $1 \%$ (100-year return period); after the changepoint, probabilities of annual maximum tidal levels being above $5.17 \mathrm{~m}, 4.70 \mathrm{~m}, 4.29 \mathrm{~m}, 3.97 \mathrm{~m}$, and $4.06 \mathrm{~m}$ were $5.5 \%$, $8.3 \%, 9.3 \%, 10.5 \%$, and $8.6 \%$, respectively (corresponding to 18-, 12-, 11-, 10-, and 12-year return periods). Accordingly, 


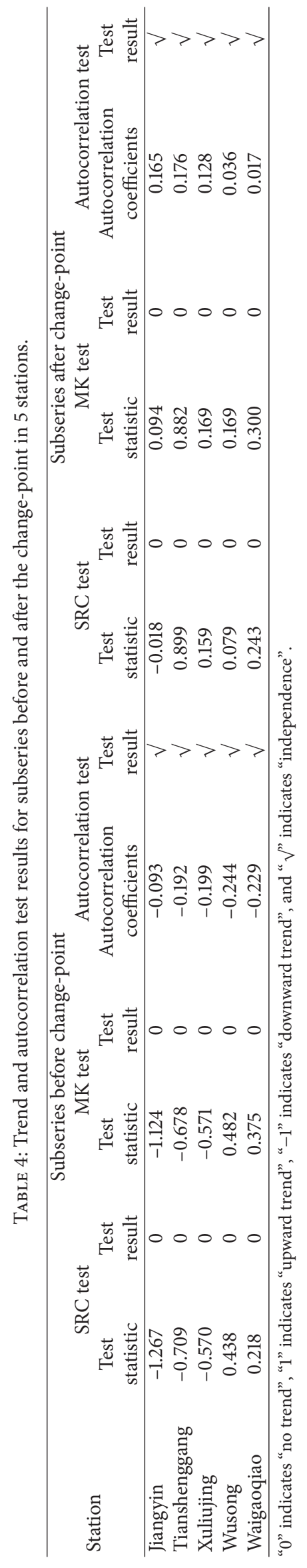




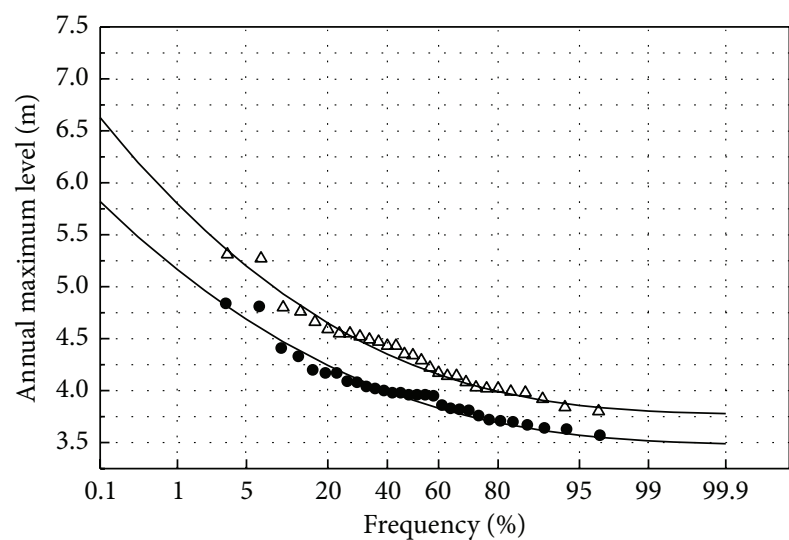

- Before change

$\triangle$ After change

(a) Jiangyin

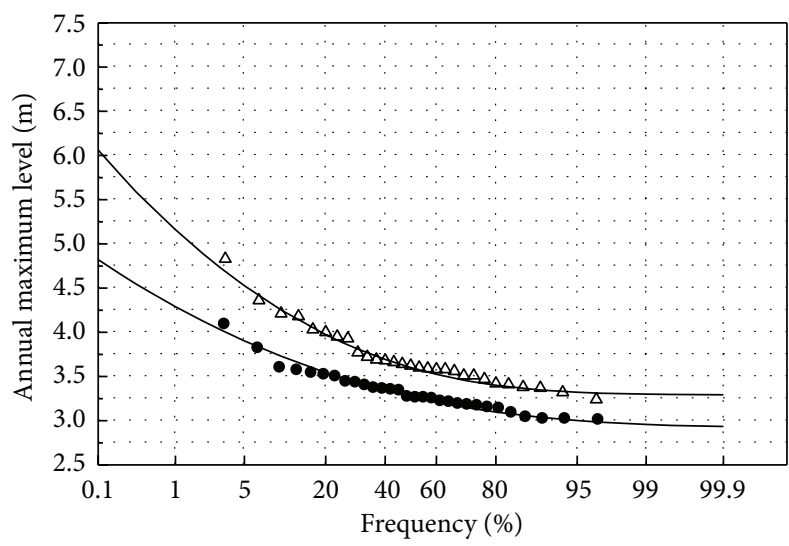

- Before change $\Delta$ After change

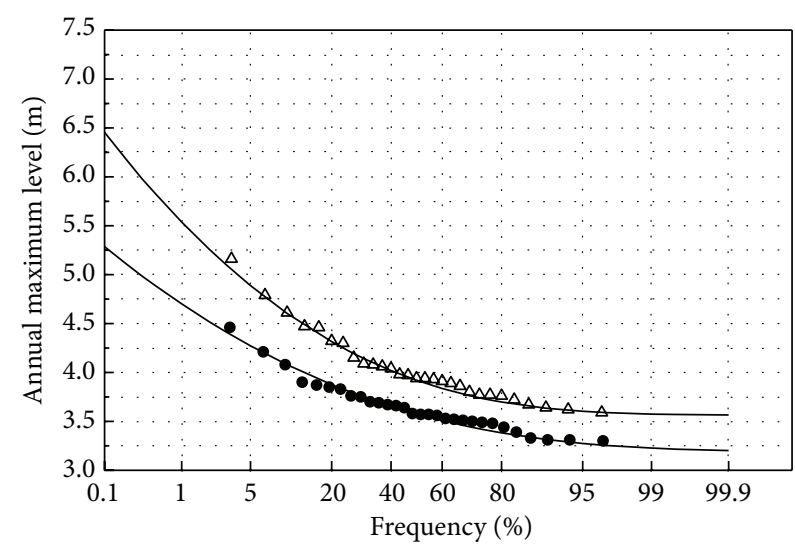

- Before change

$\Delta$ After change

(b) Tianshenggang

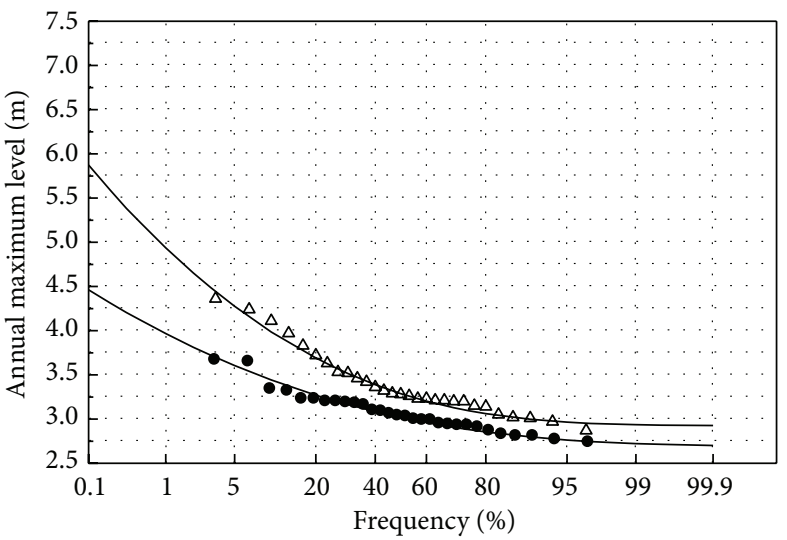

- Before change

$\Delta$ After change

(c) Xuliujing

(d) Wusong

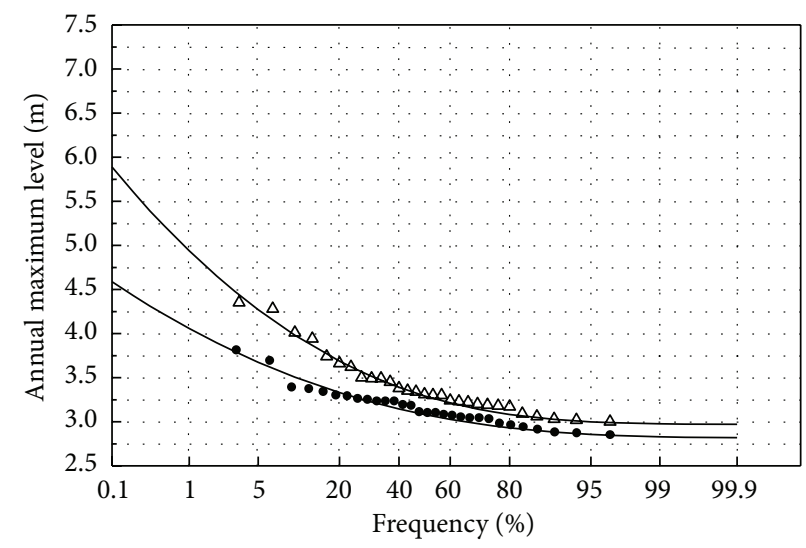

- Before change

$\triangle$ After change

(e) Gaoqiao

FIGURE 7: Frequency curves of the annual maximum tidal level subseries before and after the change-point in each station. 
TABLE 5: Distribution parameters and design values of the annual maximum tidal level subseries before and after the change-point in each station.

\begin{tabular}{|c|c|c|c|c|c|c|c|c|c|c|}
\hline \multirow{2}{*}{ Station } & \multirow{2}{*}{ Series } & \multirow{2}{*}{ EX } & \multirow{2}{*}{$C_{V}$} & \multirow{2}{*}{$C_{S}$} & \multicolumn{6}{|c|}{ Frequency (\%) } \\
\hline & & & & & 0.1 & 0.2 & 1 & 2 & 5 & 10 \\
\hline \multirow{3}{*}{ Jiangyin } & B & 3.99 & 0.090 & 1.40 & 5.82 & 5.63 & 5.17 & 4.96 & 4.69 & 4.47 \\
\hline & A & 4.35 & 0.100 & 1.50 & 6.63 & 6.38 & 5.80 & 5.54 & 5.20 & 4.93 \\
\hline & $A-B$ & 0.36 & & & 0.81 & 0.76 & 0.63 & 0.58 & 0.51 & 0.46 \\
\hline \multirow{3}{*}{ Tianshenggang } & B & 3.65 & 0.088 & 1.40 & 5.29 & 5.11 & 4.70 & 4.52 & 4.27 & 4.08 \\
\hline & $\mathrm{A}$ & 4.04 & 0.106 & 1.80 & 6.46 & 6.18 & 5.54 & 5.26 & 4.89 & 4.60 \\
\hline & A-B & 0.39 & & & 1.17 & 1.07 & 0.84 & 0.74 & 0.62 & 0.53 \\
\hline \multirow{3}{*}{ Xuliujing } & B & 3.34 & 0.087 & 1.40 & 4.82 & 4.66 & 4.29 & 4.13 & 3.90 & 3.73 \\
\hline & $\mathrm{A}$ & 3.72 & 0.109 & 1.90 & 6.06 & 5.79 & 5.16 & 4.89 & 4.53 & 4.25 \\
\hline & A-B & 0.38 & & & 1.24 & 1.13 & 0.87 & 0.76 & 0.62 & 0.52 \\
\hline \multirow{3}{*}{ Wusong } & $\mathrm{B}$ & 3.08 & 0.088 & 1.40 & 4.46 & 4.31 & 3.97 & 3.81 & 3.61 & 3.44 \\
\hline & A & 3.41 & 0.128 & 1.80 & 5.87 & 5.59 & 4.94 & 4.65 & 4.28 & 3.99 \\
\hline & A-B & 0.33 & & & 1.41 & 1.28 & 0.97 & 0.84 & 0.67 & 0.54 \\
\hline \multirow{3}{*}{ Gaoqiao } & B & 3.15 & 0.085 & 1.40 & 4.59 & 4.43 & 4.06 & 3.89 & 3.68 & 3.51 \\
\hline & $\mathrm{A}$ & 3.42 & 0.125 & 1.90 & 5.89 & 5.60 & 4.94 & 4.65 & 4.27 & 3.98 \\
\hline & A-B & 0.27 & & & 1.30 & 1.17 & 0.88 & 0.76 & 0.60 & 0.47 \\
\hline
\end{tabular}

"B" indicates subseries before change-point, "A" indicates subseries after change-point, and "A-B" indicated the difference between the subseries before and after change-point.

after the change-point, probability of annual maximum level exceeding the same value increased significantly.

\section{Conclusions}

In this paper, the efficiencies of different trend and changepoint detection methods were investigated through Monte Carlo simulation, and the nonstationarity of annual maximum level records in the Yangtze River estuary was analyzed. The main conclusions were as follows:

(1) Based on statistical experiments, it was found that the efficiency of MK test was almost the same as that of the SRC test. Test efficiency depended on the amplitude and duration of trend changes, and the amplitude of random fluctuation. For short time series with small trend change magnitude and big random fluctuation, the trend test efficiency was low, while for long time series with big trend changes magnitude and small random fluctuation test efficiency was above $90 \%$.

(2) Based on statistical experiments, it was found that the efficiencies of MT test, MRS test, and Pettitt test were almost the same. Test efficiency depended on the amplitude of shift in mean and the amplitude of random fluctuation. For the sequence with big shift in mean and small random fluctuation, test efficiency was high. For SQMK test widely used in change-point detection currently, the detection efficiency was very low. It was suggested that other methods with higher efficiency than SQMK be used in related studies in the future.

(3) Significant tendency changes existed in annual maximum tidal level series at all selected stations in the Yangtze River estuary. 1980 and 1979 were statistically significant change-points. Frequency increase of typhoons and storage capacity decrease of the local river channel were main causes for nonstationary change of annual maximum tidal level. Results of trend and independence test for the subseries before and after the change-points showed that the subseries can be accepted as stationary series without serial correlation.

(4) Through frequency analysis on the subseries before and after the change-point in all these stations, it was found that obvious changes took place in probability distribution of annual maximum tidal level in the Yangtze River estuary. For every station, compared with the conditions before the changepoint, design high tidal level for the same frequency after the change-point increased significantly. Meanwhile, risks of exceeding the same extreme after the change-point also increased significantly. The changes in probability distribution should be considered in determining design high tidal levels for flood protection measures.

\section{Conflict of Interests}

The authors declare that there is no conflict of interests regarding the publication of this paper.

\section{Acknowledgments}

This research was supported by the National Natural Science Foundation of China (no. 51479061) and the Main Program of National Natural Science Foundation of China (no. 51190091). 
The authors would like to thank the anonymous reviewers for their comments permitting improvement of the paper.

\section{References}

[1] P. C. D. Milly, J. Betancourt, M. Falkenmark et al., "Stationarity is dead: whither water management?" Science, vol. 319, no. 5863, pp. 573-574, 2008.

[2] H. B. Mann, "Nonparametric tests against trend," Econometrica, vol. 13, pp. 245-259, 1945.

[3] M. G. Kendall, Rank Correlation Methods, Charless Griffin, London, UK, 1975.

[4] C. T. Haan, Statistical Methods in Hydrology, The Iowa State University Press, Ames, Iowa, USA, 1977.

[5] Q. Wang and C. B. Fu, "The detection of climate abrupt change with Mann-Kendall rank statistics," Acta Meteorologica Sinica, vol. 6, no. 2, pp. 254-260, 1992.

[6] D. R. Helsel and R. M. Hirsch, Statistical Methods in Water Resources, Elsevier, 1993.

[7] A. Hess, H. Iyer, and W. Malm, "Linear trend analysis: a comparison of methods," Atmospheric Environment, vol. 35, no. 30, pp. 5211-5222, 2001.

[8] Z. W. Kundzewicz and A. J. Robson, "Change detection in hydrological records-a review of the methodology," Hydrological Sciences Journal, vol. 49, no. 1, pp. 7-19, 2004.

[9] P. Xie, G. C. Chen, H. F. Lei, and F. Y. Wu, "Hydrological alteration diagnosis system," Journal of Hydroelectric Engineering, vol. 29, no. 1, pp. 85-91, 2010 (Chinese).

[10] R. M. Hirsch and J. R. Slack, "A nonparametric trend test for seasonal data with serial dependence," Water Resources Research, vol. 20, no. 6, pp. 727-732, 1984.

[11] K. W. Potter, "Illustration of a new test for detecting a shift in mean in precipitation series," Monthly Weather Review, vol. 109, no. 9, pp. 2040-2045, 1981.

[12] T. A. Buishand, "Tests for detecting a shift in the mean of hydrological time series," Journal of Hydrology, vol. 73, no. 1-2, pp. 51-69, 1984.

[13] L. Perreault, J. Bernier, B. Bobée, and E. Parent, "Bayesian change-point analysis in hydrometeorological time series. Part 2. Comparison of change-point models and forecasting," Journal of Hydrology, vol. 235, no. 3-4, pp. 242-263, 2000.

[14] S. N. Rodionov, "A sequential algorithm for testing climate regime shifts," Geophysical Research Letters, vol. 31, no. 9, Article ID L09204, 2004.

[15] J. Reeves, J. Chen, X. L. Wang, R. Lund, and Q. Lu, "A review and comparison of changepoint detection techniques for climate data," Journal of Applied Meteorology and Climatology, vol. 46, no. 6, pp. 900-915, 2007.

[16] X. L. Wang, Q. H. Wen, and Y. Wu, "Penalized maximal t test for detecting undocumented mean change in climate data series," Journal of Applied Meteorology and Climatology, vol. 46, no. 6, pp. 916-931, 2007.

[17] O. Seidou and T. B. M. J. Ouarda, "Recursion-based multiple changepoint detection in multiple linear regression and application to river streamflows," Water Resources Research, vol. 43, no. 7, Article ID W07404, 2007.

[18] H. F. Lei, P. Xie, and G. C. Chen, "Comparison and analysis on the performance of hydrological time series change-point testing methods," Water Resources and Power, vol. 25, no. 4, pp. 36-40, 2007 (Chinese).
[19] H. Aksoy, A. Gedikli, N. E. Unal, and A. Kehagias, "Fast segmentation algorithms for long hydrometeorological time series," Hydrological Processes, vol. 22, no. 23, pp. 4600-4608, 2008.

[20] C. Beaulieu, O. Seidou, T. B. M. J. Ouarda, and X. Zhang, "Intercomparison of homogenization techniques for precipitation data continued: comparison of two recent Bayesian change point models," Water Resources Research, vol. 45, no. 8, 2009.

[21] L. H. Xiong and S. L. Guo, "Trend test and change-point detection for the annual discharge series of the Yangtze River at the Yichang hydrological station," Hydrological Sciences Journal, vol. 49, no. 1, pp. 99-112, 2004.

[22] T. Petrow and B. Merz, "Trends in flood magnitude, frequency and seasonality in Germany in the period 1951-2002," Journal of Hydrology, vol. 371, no. 1-4, pp. 129-141, 2009.

[23] H. Fan, Y. X. Liu, and H. J. Huang, "Long-term trend and change point analysis on runoff and sediment fluxes into the sea from the Yellow River during the period of 1950-2007," Journal of Sediment Research, no. 5, pp. 9-16, 2009 (Chinese).

[24] P. Schmocker-Fackel and F. Naef, "More frequent flooding? Changes in flood frequency in Switzerland since 1850," Journal of Hydrology, vol. 381, no. 1-2, pp. 1-8, 2010.

[25] G. Villarini, J. A. Smith, F. Serinaldi, and A. A. Ntelekos, "Analyses of seasonal and annual maximum daily discharge records for central Europe," Journal of Hydrology, vol. 399, no. 3-4, pp. 299-312, 2011.

[26] E. Morán-Tejeda, J. I. López-Moreno, A. Ceballos-Barbancho, and S. M. Vicente-Serrano, "River regimes and recent hydrological changes in the Duero basin (Spain)," Journal of Hydrology, vol. 404, no. 3-4, pp. 241-258, 2011.

[27] G. Mouri, S. Kanae, and T. Oki, "Long-term changes in flood event patterns due to changes in hydrological distribution parameters in a rural-urban catchment, Shikoku, Japan," Atmospheric Research, vol. 101, no. 1-2, pp. 164-177, 2011.

[28] H.-J. Chu, T.-Y. Pan, and J.-J. Liou, "Change-point detection of long-duration extreme precipitation and the effect on hydrologic design: a case study of south Taiwan," Stochastic Environmental Research and Risk Assessment, vol. 26, no. 8, pp. 1123-1130, 2012.

[29] P. Sonali and D. N. Kumar, "Review of trend detection methods and their application to detect temperature changes in India," Journal of Hydrology, vol. 476, pp. 212-227, 2013.

[30] G. F. Li, A. P. Chen, and J. P. Hua, "Problems and improvements in design tidal level calculation," Water Resources and Power, vol. 24, no. 3, pp. 35-38, 2006 (Chinese).

[31] C. B. Fu and Q. Wang, "The definition and detection of the abrupt climatic change," Scientia Atmospherica Sinica, vol. 16, no. 4, pp. 482-493, 1992.

[32] A. N. Pettitt, "A non-parametric approach to the change-point problem," Applied Statistics, vol. 28, no. 2, pp. 126-135, 1979.

[33] R. Sneyers, On the Statistical Analysis of Series of Observations, vol. 143, Technote International, Geneva, Switzerland, 1990.

[34] J. A. Greenwood, J. M. Landwehr, N. C. Matalas, and J. R. Wallis, "Probability weighted moments: definition and relation to parameters of several distributions expressable in inverse form," Water Resources Research, vol. 15, no. 5, pp. 1049-1054, 1979.

[35] D. D. Song and J. Ding, "The application of probability weighted moments to estimating the parameters for Pearson type-III distribution," Journal of Hydraulic Engineering, vol. 3, pp. 1-11, 1988. 
[36] X. F. Ma, "Weighted function method in calculating parameters of hydrological frequency distribution," Journal of China Hydrology, vol. 21, no. 3, pp. 1-8, 1984 (Chinese).

[37] Z. M. Liang and H. Zhang, "A modified double-weighted function method," Journal of Hohai University (Natural Sciences), vol. 29, no. 6, pp. 20-23, 2001 (Chinese).

[38] J. R. Hosking, " $L$-moments: analysis and estimation of distributions using linear combinations of order statistics," Journal of the Royal Statistical Society Series B: Methodological, vol. 52, no. 1, pp. 105-124, 1990.

[39] A. Sankarasubramanian and K. Srinivasan, "Investigation and comparison of sampling properties of L-moments and conventional moments," Journal of Hydrology, vol. 218, no. 1-2, pp. 1334, 1999.

[40] S. L. Guo, Advance and Assessment of Design Flood Methods, China Water Power Press, Beijing, China, 2005 (Chinese).

[41] Ministry of Water Resources of China, Regulation for Calculating Design Flood of Water Resources and Hydropower Projects, China Water Power Press, Beijing, China, 2006 (Chinese).

[42] X. N. Li, P. Xie, B. Xu, and Y. Liu, "Algorithm and application of inconsistent flood frequency based on the MISOHRM model (II): temporal and spatial alteration analysis," Journal of Water Resources Research, vol. 1, pp. 310-314, 2012 (Chinese).

[43] G. F. Li, Z. P. Huang, Z. Q. Zhang, and S. Ye, "Risk analysis of design flood stage of Nanjing section of Yangtze River floodprotecting embankment," Journal of Hohai University (Natural Sciences), vol. 27, no. 2, pp. 22-27, 1999 (Chinese).

[44] G. F. Li, X. Y. Xiang, J. Wu, and Y. Tan, "Long-term water-level forecasting and real-time correction models in the tidal reach of the Yangtze river," Journal of Hydrologic Engineering, vol. 18, no. 11, pp. 1437-1442, 2013.

[45] N. X. Qin, T. Jiang, and C. Y. Xu, "Trends and abruption analysis on the discharge in the Yangtze Basin," Resources and Environment in the Yangtze Basin, vol. 14, no. 5, pp. 589-594, 2005.

[46] E. M. Douglas, R. M. Vogel, and C. N. Kroll, "Trends in floods and low flows in the United States: impact of spatial correlation," Journal of Hydrology, vol. 240, no. 1-2, pp. 90-105, 2000.

[47] T. Yang, Q. X. Shao, Z.-C. Hao et al., "Regional frequency analysis and spatio-temporal pattern characterization of rainfall extremes in the Pearl River Basin, China," Journal of Hydrology, vol. 380, no. 3-4, pp. 386-405, 2010. 

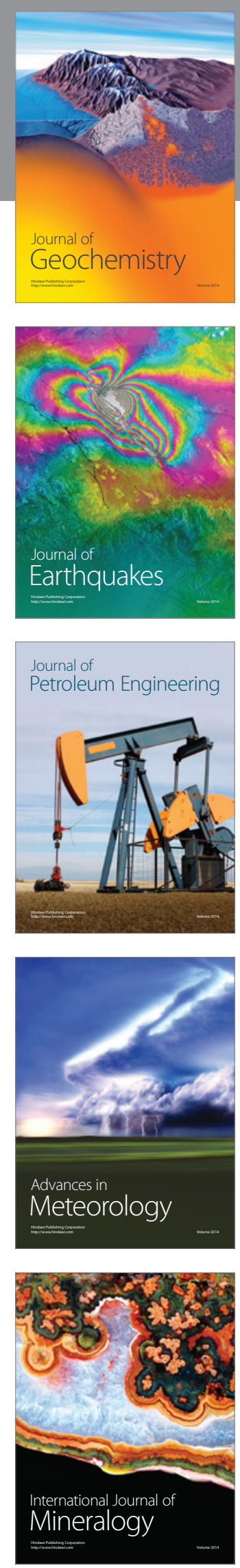
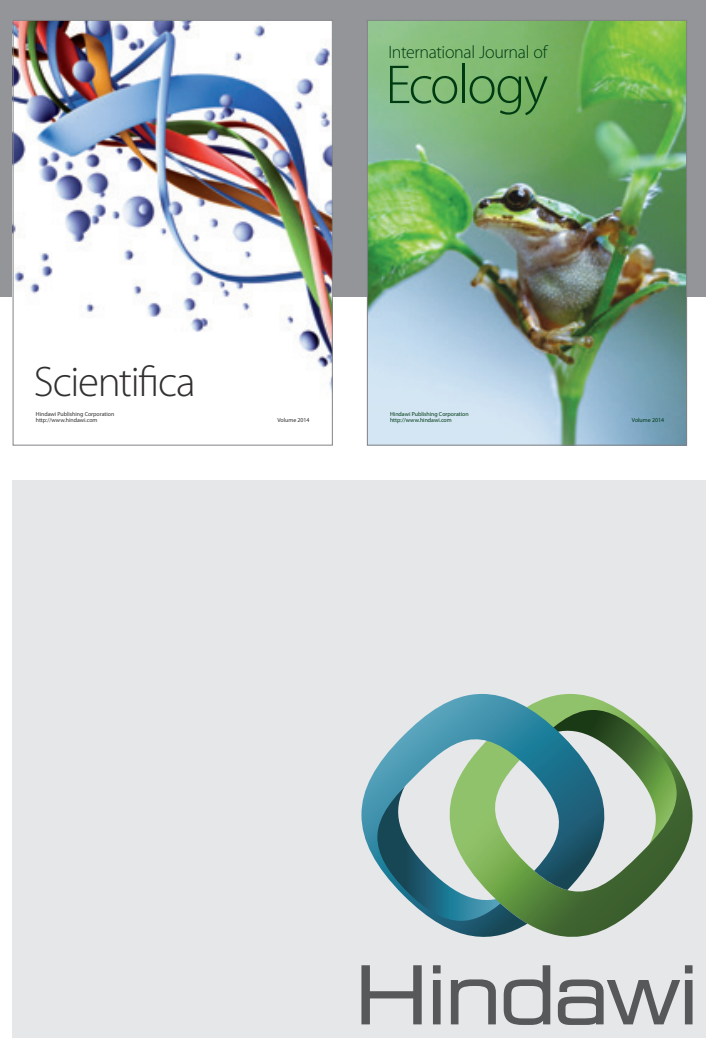

Submit your manuscripts at

http://www.hindawi.com
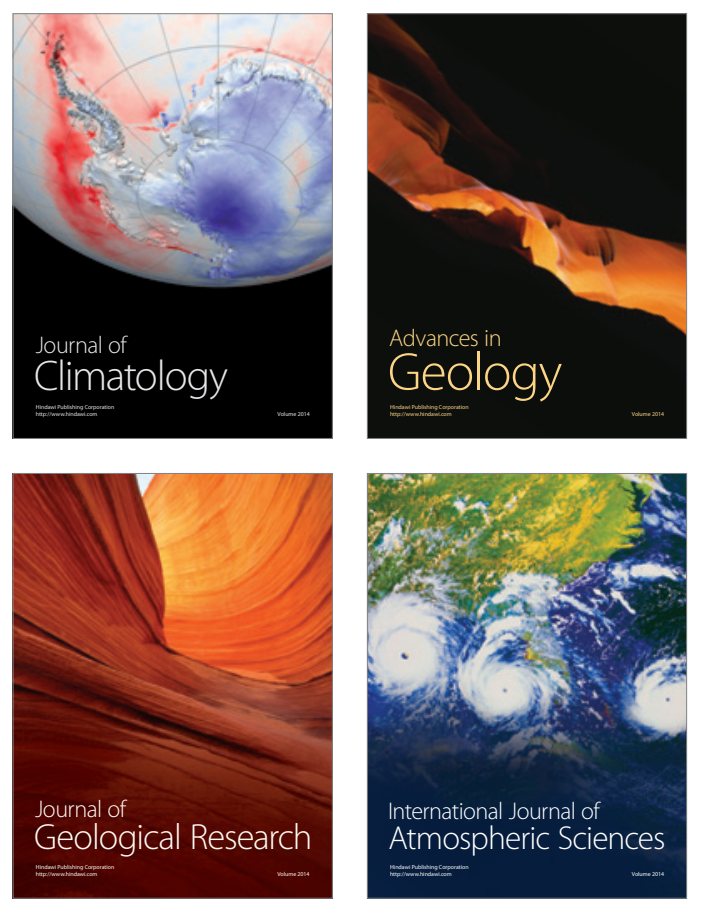

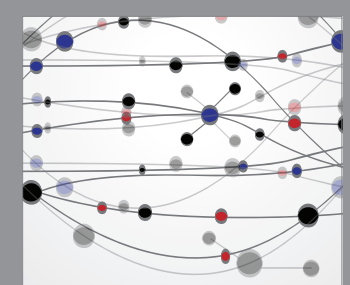

The Scientific

\section{World Journal}
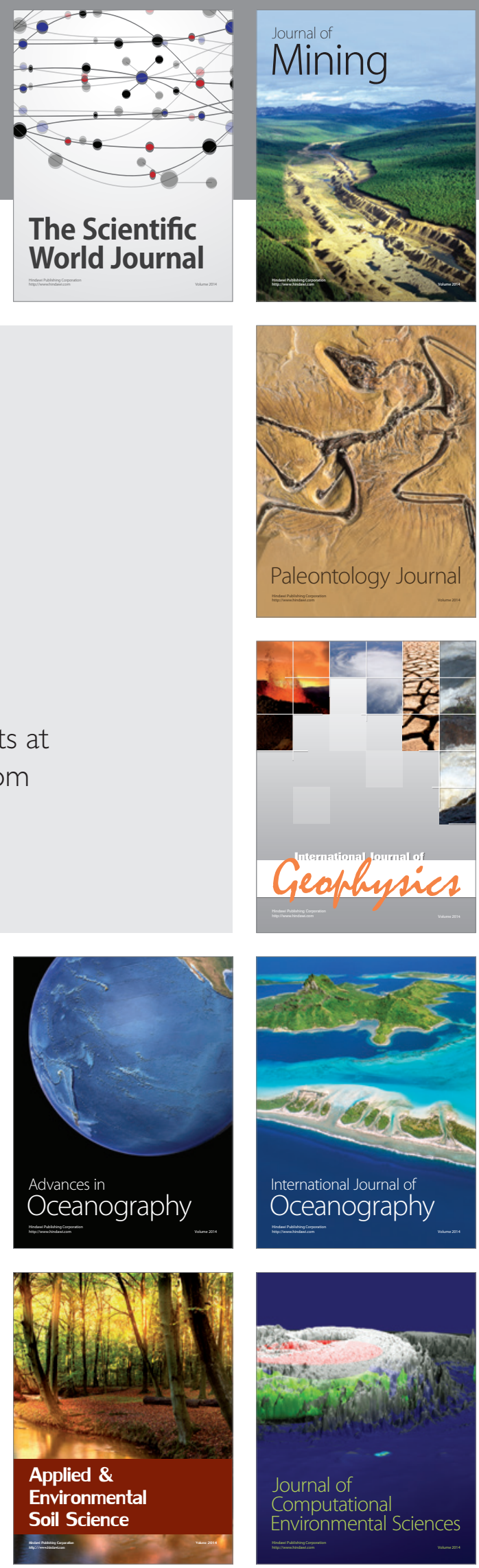